\title{
DISCIPLINA E INDISCIPLINA ESCOLAR EM TEMPOS DE SOCIEDADE EXCITADA
}

\author{
School discipline and indiscipline in times of excited society
}

\begin{abstract}
RESUMO Este trabalho se propõe a ler criticamente as abordagens pedagógicas brasileiras a respeito da disciplina e a indisciplina escolar fundamentando-se em estudos contemporâneos que discutem as transformações da percepção humana decorrentes do desenvolvimento da cultura midiática. Com o intuito de contribuir para o estudo dessas mudanças no campo pedagógico, o trabaIho está organizado em três partes. A primeira seção apresenta as abordagens de disciplina e indisciplina escolar realizadas nos Programas de Pós-Graduação em Educação no Brasil no período de 2009 a 2013. A segunda seção discorre a respeito do pensamento de Adorno e Türcke em relação às modificações culturais no desenvolvimento do capitalismo e suas manifestações acerca da percepção humana. A terceira e última seção, apoiada no pensamento desses filósofos, problematiza os estudos pedagógicos especialmente por não discutirem a disciplina e a indisciplina dentro de uma relação dialética com as transformações sociais e perceptivas ocorridas e em curso na cultura contemporânea.
\end{abstract}

PALAVRAS-ChAVE: DISCIPLINA; INDISCIPLINA; SEMIFORMAÇÃO; SOCIEDADE EXCITADA.

ABSTRACT This work proposes the critical view of Brazilian pedagogic approaches on school discipline and indiscipline based on contemporary studies that discuss the transformations of human perception originated from the development of media culture. With the intent of contributing in the study of these changes in the pedagogic field, this work is organized in three parts. The first section presents the approaches of school discipline and indiscipline performed in the Graduation Programs in Education in Brazil, during the period of 2009 and 2013. The second discusses on the thoughts of Adorno and Türcke regarding the cultural changes in the development of capitalism and its manifestations over human perception. The third and last section, supported by the thoughts of these philosophers, problematizes the pedagogic studies, especially for not discussing discipline and indiscipline within a dialectic relation with social transformations and perspectives occurred and in course of contemporary culture.

KEY-WORDS: DISCIPLINE; INDISCIPLINE; SEMI-EDUCATION; EXCITED SOCIETY.

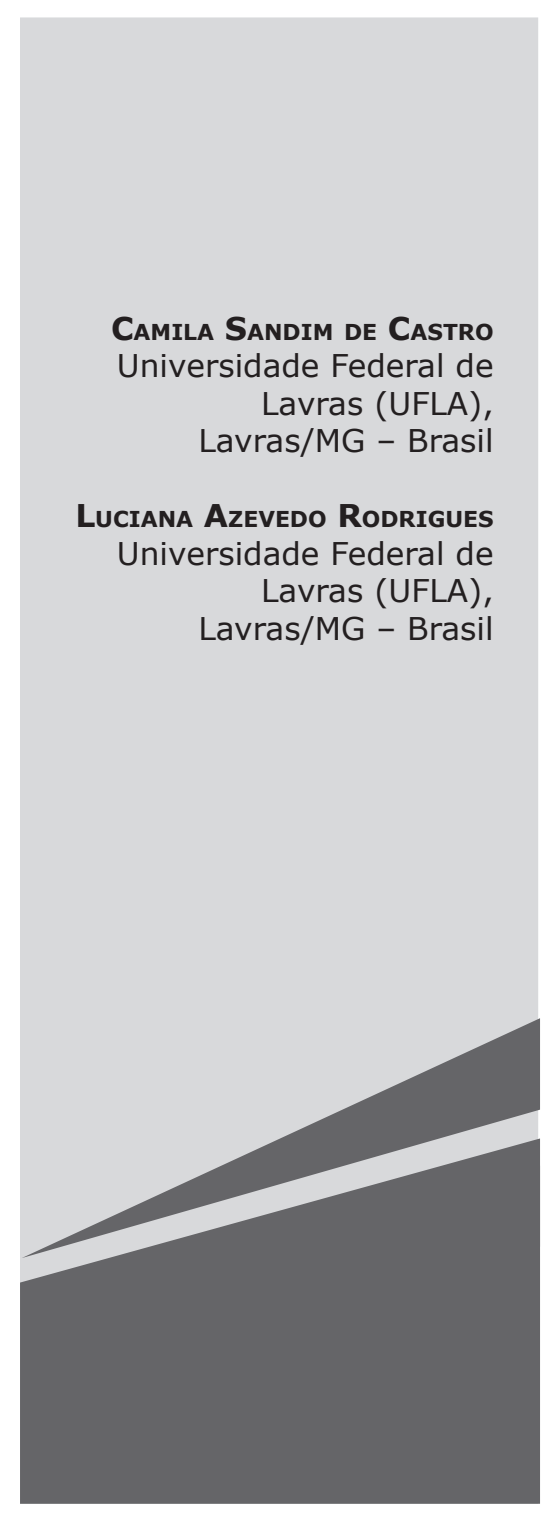




\section{INTRODUÇÃO}

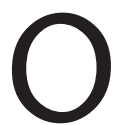

eresse em discutir e problematizar

a disciplina e a indisciplina no pro-

cesso educativo surgiu no decorrer da Graduação em Educação Física (Licenciatura), especialmente na experiência dos estágios supervisionados na Educação Básica, com a observação de que as exigências de disciplina feitas pelos professores aos seus alunos aconteciam durante todo o período de permanência dos discentes na escola, inclusive no intervalo entre as aulas. Apesar de tais exigências, era possível perceber que, na maior parte das vezes, os alunos não davam muita atenção às solicitações de disciplina feitas por seus professores.

O magistério experimentado em três escolas da rede estadual de ensino de Minas Gerais permitiu perceber a naturalização da indisciplina e os momentos em que alguns professores se eximiram da responsabilidade de planejarem suas aulas, especialmente quando acabaram se omitindo diante das atitudes indisciplinadas de seus alunos. Paralelamente à experiência dos estágios e da docência, os estudos de obras de pensadores da Teoria Crítica da Sociedade, principalmente Theodor W. Adorno e Christoph Türcke, permitiram verificar a importância do disciplinamento para o processo formativo. Adorno, apesar de não ter tratado explicitamente das questões que envolvem a (in)disciplina escolar, oferece elementos para refletir acerca de tal conceito ao reconhecer a importância da autoridade docente para o processo formativo, como é possível observar em "Teoria da Semiformação” (2010). A (in)disciplina também não é objeto de estudo de Türcke, mas sua discussão acerca das mudanças nas formas de pensar e sentir ocasionadas pelo desenvolvimento tecnológico, como é abordado em "Sociedade excitada: filosofia da sensação" (2010a), possibilita refletir sobre a (in)disciplina discente em uma sociedade cada vez mais marcada pela dificuldade de concentração.

Nesse contexto, uma das medidas para a obtenção da disciplina dos alunos, observada na experiência dos estágios supervisio- nados e no magistério, foi a proibição do uso de aparelhos eletrônicos no espaço escolar devido ao entendimento de que eram eles os causadores da dispersão dos estudantes e da indisciplina nas aulas. A desobediência chegava a ser punida com a subtração de pontos das notas bimestrais, encaminhamentos para a direção da escola, advertências, repetências, suspensões e expulsões. Ou seja, em vez de se indagarem acerca das motivações da indisciplina no contexto cultural contemporâneo, problematizando-as no interior de processos históricos e sociais, tais práticas escolares buscavam canalizar as causas da indisciplina apenas à utilização dos aparelhos eletrônicos por parte dos alunos. Mas como a realidade mesma da escola insiste em apontar, o mundo contemporâneo constituiu-se com o progresso tecnológico, com a produção de aparatos e subjetividades novas, que exige pensar suas diferenças ou não dos mecanismos de controle praticados pela escola, como descrito por Michel Foucault na década de 1970, sobretudo em "Vigiar e Punir" (2010), e abordados ainda em estudos recentes. Ou seja, as mudanças sociais exigem que a escola não assuma uma postura proibitiva em relação aos aparelhos tecnológicos, mas que realize incursões no sentido mesmo de compreender as relações efetivas entre eles, as transformações sociais e as manifestações de indisciplina verificadas na escola.

Com a compreensão de que a disciplina continua sendo requerida em demasia nos espaços escolares, mas pouco discutida e refletida por professores e alunos, e que os pensadores mencionados permitem pensar numa dimensão formativa da disciplina, este artigo propõe-se a realizar uma leitura crítica das abordagens pedagógicas brasileiras a respeito da disciplina e a indisciplina escolar, fundamentando-se em estudos contemporâneos que discutem as transformações da percepção humana decorrentes do desenvolvimento da cultura midiática.

Tal problematização fundamenta-se na Teoria Crítica da Sociedade, especialmente, na compreensão de Christoph Türcke em 
"Sociedade excitada: filosofia da sensação" (2010a), de que nas transformações sociais que produziram a cultura midiática, a percepção humana também sofreu mutações, às quais exigem também o repensar daquilo que vem sendo compreendido como disciplina e indisciplina.

Além de expor as críticas presentes nas abordagens pedagógicas, a primeira seção evidencia a predominância do pensamento de Michel Foucault como referencial teórico utilizado por essas abordagens e a frequência que tais temas foram estudados nos últimos anos. A segunda seção traz reflexões desenvolvidas por Theodor W. Adorno e Christoph Türcke sobre as transformações sociais provocadas com o avanço técnico e tecnológico e suas expressões nos processos educativos, principalmente a respeito da disciplina e a indisciplina discente. A terceira e última seção tece considerações críticas acerca das abordagens apresentadas na primeira parte, tendo como fundamentação as teorias sobre as transformações perceptivas desenvolvidas por Adorno e Türcke exibidas na segunda seção.

\section{A (IN)DISCIPLINA ESCOLAR NOS ESTUDOS PEDAGÓGICOS CONTEMPORÂNEOS}

O incômodo com o modo meramente punitivo de tratar a indisciplina na escola e, ao mesmo tempo, a preocupação em pensar a dimensão formativa da disciplina para o processo educativo impulsionaram a realização de um primeiro levantamento de teses e dissertações acerca da disciplina e da indisciplina escolar produzidas no período de 2009 a 2013. A busca foi realizada nos endereços eletrônicos do Banco de Teses da Coordenação de Aperfeiçoamento de Pessoal de Nível Superior (CAPES) e no da Biblioteca Digital Brasileira de Teses e Dissertações (BDTD). Os descritores utilizados foram disciplina escolar, indisciplina escolar, (in)disciplina e educação, (in)disciplina e formação de professores, (in)disciplina discente, (in)disciplina no processo educativo. Com essa busca, pretendeu-se conhecer como os estudos pedagógicos contemporâneos produzidos na área da Edu- cação têm compreendido a disciplina e a indisciplina escolar.

Por meio da leitura dos resumos, foram encontradas 25 dissertações de mestrado que abordavam o assunto, porém, não foi achada tese de doutorado alguma que se debruçasse sobre a disciplina e/ou indisciplina escolar durante o período investigado. $\mathrm{O}$ que levou a pensar que o tema não tem sido muito discutido nos Programas de Pós-Graduação em Educação no Brasil. Dessas 25 dissertações, nove foram defendidas em 2009, quatro em 2010, sete em 2011 e cinco em 2012.

Os trabalhos selecionados para este estudo são provenientes de dois critérios de seleção, o primeiro se refere ao fato de as dissertações terem sido produzidas no interior de Programas de Pós-Graduação em Educação, e o segundo está relacionado com o maior aprofundamento das ideias, reconhecido na primeira leitura do texto. Assim, de 25 dissertações, identificamos dezenove oriundas de Mestrado em Educação, duas de Mestrado em Psicologia, uma de Mestrado em Linguística Aplicada, uma de Mestrado em Psicologia Clínica e duas de Mestrado em Sociologia. Dos dezenove estudos encontrados na área da Educação, selecionamos nove dissertações por meio da leitura dos resumos e das partes introdutória e conclusiva. Desses estudos, cinco dissertações foram defendidas em 2009, três em 2010 e uma em 2011, acenando para um afastamento das pesquisas educacionais em relação ao tema. A realização de uma primeira leitura das nove dissertações permitiu constatar que, para discutir a disciplina e a indisciplina no processo educativo, cinco trabalhos se sustentaram, especialmente no pensamento do filósofo francês Michel Foucault.

Um dos estudos encontrados, defendido por Pereira (2009), considera que a indisciplina está associada a comportamentos que se opõem às normas estabelecidas pelas instituições de ensino. Entendida, em muitos casos como responsabilidade da família, o estudo aponta que a indisciplina não é percebida como algo que se desenvolve no interior da 
relação entre os agentes educacionais, o que leva a uma "psicologização" da gênese da indisciplina, enredada a características individuais dos alunos como a falta de limites, a desatenção, o desinteresse e a pouca motivação para os estudos. Santos (2011) compartilha a mesma compreensão de indisciplina discutida por Pereira (2009), ao considerá-la uma expressão do descompromisso da família na educação de seus filhos e da não aceitação dos alunos em relação às normas impostas pela escola. Segundo Santos (2011), as instituições de ensino desejam manter o controle sobre o corpo discente ao mesmo tempo em que os alunos resistem às regras impostas pela escola. Os estudos chamam a atenção para a indisciplina como resposta às formas de controle do corpo praticadas na escola, ao passo que criticam a perspectiva que explica a indisciplina como resultado da ausência de arranjos socioafetivos e ao desinteresse dos alunos em relação aos estudos, visto como algo a eles inerentes.

Na dissertação intitulada "Política de formação do professor de Educação Física e indisciplina escolar", Nogueira (2010) afirma que a indisciplina discente se deve a um conjunto de fatores que estão diretamente inseridos no interior das relações escolares, como o despreparo dos agentes educacionais, a má estrutura física e gerencial da escola e a não efetivação das políticas educacionais. A autora assevera que a indisciplina também está associada a fatores que, mesmo não estando introduzidos profundamente no espaço escolar, fazem parte dele, ao modificar as ações e os comportamentos dos agentes educacionais, como é o caso da família "[...] que não assume a sua responsabilidade frente à educação de seus filhos, negando apoio emocional e a sua não participação na vida escolar da criança" (NOGUEIRA, 2010, p. 98). E dos meios de comunicação "[...] como a mídia, aqui compreendida aos programas televisivos e de internet de cunho pornográfico e agressivo, de fácil acesso às crianças em fase da construção de sua personalidade e seus valores" (NOGUEIRA, 2010, p. 98). Ou seja, encontra-se nos textos um olhar crítico ao espaço escolar como produtor de indisciplina e um compromisso de desnaturalizá-la, atribuindo-a como um traço de determinados estudantes provenientes das chamadas "famílias desestruturadas".

Diferente de Nogueira (2010), que aponta a existência de fatores extraescolares na indisciplina escolar, Gross (2009) afirma que há nas escolas pesquisadas uma tentativa de "fabricar" o aluno por meio do processo de disciplinamento com o objetivo de minimizar sua capacidade de resistência e reprimir sua liberdade em sala de aula. $O$ que o leva a assumir uma posição contrária à das professoras entrevistadas em sua própria pesquisa, que consideram a disciplina como algo positivo para a formação ao entenderem "a disciplinação como algo contínuo, mesmo quando atuando em intervalos pequenos de tempo, como as aulas" (GROSS, 2009, p. 11). A dissertação intitulada "Indisciplina escolar na visão de coordenadores pedagógicos", escrita por Mendes (2009), aproxima-se das discussões feitas por Gross (2009), por entender a indisciplina como um modo de contestação do estudante em relação a "[...] normas, esquemas, regras e valores propondo desta forma um pensar sobre o que é praticado pela escola" (MENDES, 2009, p. 114). Esse entendimento faz que Mendes (2009) afirme que a indisciplina é uma "forma de inteligência" do aluno, pois demonstra o incômodo do estudante ao que lhe parece inapropriado na prática docente. Ainda, segundo Mendes (2009), o discente age de maneira indisciplinada ao não ter suas necessidades e anseios atendidos pela escola, desse modo, exprime a sua insatisfação frente às formas de ensino que lhe são oferecidas.

Havenstein (2009) também entende a indisciplina, assim como Gross (2009) e Mendes (2009), como sinônimo de resistência. Adverte, ainda, que as diferentes práticas pedagógicas desenvolvidas nas escolas camuflam o verdadeiro objetivo da educação escolar, que seria o disciplinamento do corpo conseguido, ao incutir o medo nos alunos a fim de que tenham comportamentos socialmente aceitos. Assim, 
para a autora a escola como local de vigilância e controle promove uma espécie de disciplinamento disfarçado que tem como objetivo a produção de sujeitos não contestadores.

Fonseca (2009) também compreende a indisciplina como resistência, afirmando que, apesar das escolas tentarem manter a "disciplinação" dos corpos infantis, em muitos momentos elas não conseguem fazê-lo, pois em sua própria prática pedagógica acabam criando modos de resistência. Nas palavras da autora: "as práticas pedagógicas exigem corpos silenciosos, enfileirados, organizados, docilizados, prontos para agir a partir de um comando" (FONSECA, 2009, p. 93). Assim, segundo a pesquisadora, as ações praticadas no interior das escolas têm como finalidade promover o adestramento e o disciplinamento dos corpos. Outro estudo realizado, em 2010, por Teixeira, compreende que a indisciplina está relacionada à maneira como professores e alunos atuam na sala de aula, especificamente no que se refere à diferença dos ritmos adotados para a realização de suas atividades. Enquanto os professores demonstram uma necessidade de organização e de assumir um ritmo compassado no desenvolvimento de sua prática docente, os alunos se mostram desapegados da rotina, da organização e da previsibilidade. Apesar de identificar o descompasso entre professores e alunos e compreender a indisciplina como manifestação da repulsa dos alunos em agir como determina a escola, a discussão de Teixeira (2010) não acena na direção de pensar o referido descompasso no interior das relações sociais contemporâneas.

Por fim, assim como Havenstein (2009), Fonseca (2009), Nogueira (2010), Teixeira (2010) e Santos (2011) que utilizaram as discussões de Michel Foucault para subsidiar teoricamente suas pesquisas, Moura (2010) reitera que as práticas pedagógicas têm levado à fabricação de sujeitos dóceis, úteis e submissos às estratégias do poder e que a produção de tais sujeitos é conseguida mediante "[...] um controle minucioso sobre o corpo dos indivíduos por meio dos exercícios de domínio sobre o tempo, espaço, movimento, gestos e atitudes para produzir corpos submissos, exercitados e dóceis" (MOURA, 2010, p. 1516). É dessa maneira que, conforme a autora, as escolas funcionam como instituições de "sequestro" em que a utilização de técnicas de disciplinamento de controle espaço-temporal do corpo pretende estabelecer um padrão considerado "normal".

As nove dissertações encontradas compartilham a compreensão de que a indisciplina é um sinal de oposição às normas instituídas pelas instituições de ensino, e nesse sentido tem sido produzida e reproduzida no interior da escola, que vem realizando seu papel de docilizar os corpos dos indivíduos. Com isso, os estudos criticam as tentativas de naturalizar a indisciplina, compreendendo-a como uma deficiência de determinados estudantes. Tal perspectiva crítica neles presente, entretanto, não concede espaço para pensar a disciplina e a indisciplina no contexto das transformações sociais vivenciadas ao longo dos últimos anos com o avanço dos meios de comunicação de massa, apesar de terem sido realizados nesse contexto.

\section{(IN)DISCIPLINA, SEMIFORMAÇÃO E DISTRAÇÃO CONCENTRADA}

Em sua conferência intitulada "Teoria da Semiformação" Adorno, fala sobre a crise da formação cultural e o avanço de um espírito objetivo por ele denominado de Semiformação (Halbbildung) que se desenvolveu com a mercadorização da cultura. Ao compreender que a crise da Formação Cultural (Bildung) não se restringe ao contexto alemão e não pode ser algo estudado apenas no campo pedagógico, Adorno (2010) entendeu a semiformação como uma tendência social do espírito oriunda do modo alienado de se relacionar com a cultura graças ao processo de reificação produzido pelo desenvolvimento do modo de produção capitalista, que teve como principal consequência o distanciamento do indivíduo da formação cultural. Efeito da indústria cultural, a semiformação não está relacionada a um estágio inicial da formação, pois, como es- 
clarece Adorno (2010), aquilo que é "semientendido e semiexperimentado" inviabiliza a possibilidade de o indivíduo construir um conhecimento crítico acerca da realidade. Dessa maneira, a teoria da semiformação defendida por Adorno (2010) foi construída a partir do entendimento sobre o caráter dialético da cultura, ou seja, a contradição presente na cultura consiste na sujeição do indivíduo sem perder de vista a sua autonomia. Adaptação e autonomia, instrumentalização e emancipação são as bases a respeito das quais a cultura se forma. Sendo assim, conforme explica o autor, a formação cultural deve apresentar aos indivíduos a sua dimensão adaptativa de modo a inseri-los na realidade social, ao mesmo tempo, deve incitar-lhes a crítica reflexiva, o estranhamento e a resistência, para que tais indivíduos não sejam simplesmente ajustados à sociedade. Nesses termos, Adorno (2010) afirma que a formação é a apropriação subjetiva da cultura que se dá a partir da conquista da autonomia mediante a adaptação. Assim, para se tornar autônomo é preciso antes submeter-se, no entanto, o autor esclarece que na semiformação é a adaptação que prevalece sobre a autonomia ao dificultar o momento da reflexão crítica.

Expropriadas das condições objetivas para a sua formação, as pessoas estariam conformando-se com uma pseudossatisfação mobilizada com o consumo acrítico dos produtos culturais disseminados pela indústria cultural. Desse modo, Adorno assevera que, "por inúmeros canais, fornecem-se às massas bens de formação cultural. Neutralizados e petrificados, no entanto, ajudam a manter no devido lugar aqueles para os quais nada existe de muito elevado ou caro" (ADORNO, 2010, p. 16). Portanto, a formação oferecida pela indústria cultural aos indivíduos consiste em ajustá-los à realidade social para que permaneçam adaptados à cultura e não ofereçam possibilidades de contestar sua própria condição social. Para o autor, isso é possível "[...] ao ajustar-se o conteúdo da formação, pelos mecanismos do mercado, à consciência dos que foram excluídos do privilégio da cultura - e que tinha mesmo de ser os primeiros a serem modificados" (ADORNO, 2010, p. 16). Nesses termos, o consumo irrefletido dos bens culturais atua de modo a reiterar o existente, conservando a semiformação ao distanciar os indivíduos da possibilidade de se emanciparem.

Nesse contexto, Adorno (2010) enfatiza que as reformas pedagógicas criadas para lidar com a crise da formação cultural acabaram por agudizá-la. Isso porque, além de abrandarem “[...] as necessárias exigências a serem feitas aos que devem ser educados" (ADORNO, 2010, p. 8) tais reformas não teriam reconhecido o poder que a realidade extrapedagógica exerce sobre a educação escolar. Ao fazer a crítica às reformas escolares, Adorno (2010) esclarece que o processo educativo não pode prescindir da figura da autoridade docente, o que não se confunde com a defesa do retorno a posturas autoritárias por parte dos professores. O autor explica que a racionalidade burguesa, ao negar o papel formativo da autoridade paterna e, por sua vez, da autoridade docente, promoveu seu deslocamento para outros suportes, como as imagens disseminadas pela indústria cultural, por conseguinte, esse deslocamento contribuiu para um enfraquecimento na constituição do eu e na formação de sujeitos autônomos.

Para o autor, o declínio da autoridade compreende um processo social de destruição dos vestígios da tradição pré-burguesa, que "resultou num estado de carência de imagens e formas, em uma devastação do espírito que se apressa em ser apenas um meio, o que é, de antemão, incompatível com a formação. Nada retém o espírito, então, para um contato corporal com as ideias" (ADORNO, 2010, p. 21). Desse modo, se a autoridade como mediadora da tradição retinha o espírito para um "contato corporal com as ideias", seu declínio também implicou o enfraquecimento daquela mediação fundamental para os sujeitos desenvolverem a dedicação a algo, a capacidade de se demorar sobre os objetos, o que estamos denominando neste trabalho como disciplina. 
Nesses termos, o declínio da autoridade, ao mesmo tempo em que contribuiu para aproximar os indivíduos do consumo acrítico das imagens culturais, negou aos educandos o confronto com a tradição e extraiu as forças que precisavam para aprender algo de cor, especialmente algo que não fosse imediatamente pragmático e passível às agressivas avaliações. A respeito disso, Adorno lembra:

...quem tendo frequentado escola não terá se emocionado alguma vez com a poesia de Schiller e os poemas de Horácio que devia aprender de cor? E a quem os velhos pais não terão causado arrepios de extrema emoção quando, sem que se thes pedissem e inesperadamente, recitavam textos de que se recordavam ainda, compartilhados assim numa comunhão com os mais jovens? (ADORNO, 2010, p. 22).

Essa dedicação permitia a criação da memória que se dava a partir do contato com experiências formativas, proporcionadas pelo demorar-se sobre o material trabalhado. Nesses termos, a disciplina aparece como algo que se constrói na relação com os objetos de estudo. Ou seja, a disciplina era internalizada pelos alunos durante a aprendizagem dos conteúdos escolares como no exercício de concentração que era exigido para memorizar os textos clássicos, como abordado por Adorno (2010). Contudo, o esforço de memorizar tem aparecido nas propostas pedagógicas contemporâneas apenas como uma ferramenta para decorar fragmentos dos conteúdos disciplinares, a fim de serem usados nas avaliações escolares. Nesse sentido, o contato com o material de estudo que possibilita construir a disciplina é reduzido a uma relação superficial, tendo apenas como objetivo a memorização daquilo que tem aplicabilidade imediata. Assim, o guardar de cor que podemos visualizar no processo educativo contemporâneo é voltado principalmente para levar aos desempenhos esperados nas inúmeras avaliações.
Dessa maneira, com o declínio da autoridade docente o aluno também foi afastado das obras clássicas e do disciplinamento exigido para o desenvolvimento das atividades escolares. Em seu lugar, o que mais tem se colocado é a ideia de não ser detido diante de nada, o que também propomos chamar aqui de indisciplina. Pensando neste não deter-se diante de nada que se manifesta na contemporaneidade de diferentes formas, especialmente com as possibilidades abertas pelo espaço on-line e os aparelhos tecnológicos, podemos dizer que, parafraseando Adorno (2010), o indisciplinado se conserva em sua própria indisciplina.

Em "Sociedade excitada: filosofia da sensação" (2010a) Türcke, filósofo contemporâneo que atualiza as discussões empreendidas por Adorno, oferece-nos elementos para refletir sobre a necessidade de ser constantemente percebido a partir da discussão feita à teoria de George Berkeley. Segundo o autor, Berkeley tentou "construir toda uma teoria do conhecimento e da realidade. [...] Referia-se com isso ao fato de que [aquilo] [...] que não for sensação não existe para nós, pois não podemos compreender o mundo passando ao largo de nossos sentidos" (TÜRCKE, 2010a, p. 39). Assim, de acordo com esta teoria: "[...] o que não é notado, sentido, percebido, simplesmente não é" (TÜRCKE, 2010a, p. 39). Desse modo, o autor analisa a existência humana na sociedade da sensação a partir da proposição "Ser, é ser percebido" e afirma que a teoria de Berkeley, ou seja, que a existência das coisas se dá pela percepção e se não podem ser percebidas não existem, passa a ser válida na contemporaneidade. Para Türcke (2010a), há uma diferença entre ser física e midiaticamente percebido. A primeira quando comparada com a segunda tem menor força e possui um "efeito pálido e apagado", pois não basta ter um corpo em bom estado fisiológico, é preciso que os outros reconheçam esse corpo. Com o bombardeamento dos aparatos tecnológicos e das notícias, o indivíduo é impelido constantemente a emitir e a receber milhares de emissões. Segundo o 
autor, ao emitir, tal indivíduo torna-se percebido, não emitindo é como se não estivesse "aí". Assim, como esclarece Türcke (2010a), na sociedade midiática é preciso que se evoque continuamente a atenção para si a fim de que não desapareça.

Os aparatos tecnológicos são utilizados, nesse contexto, como ferramentas para que se tornar percebido seja possível, pois, de acordo com o autor, a existência passa a se dar pela presença das tecnologias. Logo, conforme esclarece Türcke (2010a), sem os aparelhos tecnológicos, existir corresponde a uma "não-existência viva". A necessidade de ser percebido institui uma compulsão pela emissão e pela ocupação. Na primeira o indivíduo está constantemente emitindo para se fazer notado, seja consumindo os produtos audiovisuais e/ou trabalhando no sentido de se transformar em imagem e se autopropagandear. Na compulsão pela ocupação há uma exigência de sempre se manter ocupado também com o objetivo de atender ao imperativo do "Ser, é ser percebido". Nesses termos, a redução da vida ao imperativo de ser notado expressa o enfraquecimento da formação psíquica do eu e produz uma nova necessidade que é a de se autoafirmar. Como observa Türcke (2010a), além de o indivíduo utilizar as imagens para ser reconhecido socialmente, elas também são usadas para confirmar sua própria existência. A quantidade de novos e-mails na caixa de entrada, o número de seguidores e/ou de "curtidas" nas fotos publicadas em redes sociais nutrem um sentimento de pertencimento social, possibilitando ao indivíduo convencer-se de que está midiaticamente vivo.

Türcke (2010a) afirma que a fragmentação do processo de trabalho e a expropriação do trabalhador de sua totalidade, produtos do desenvolvimento do modo de produção capitalista, se introduziram violentamente nas formas de pensamento e de percepção. Assim, “[...] quanto mais as pontas dos dedos e os movimentos oculares foram motora e refinadamente alinhavados a aparelhos microeletrônicos, mais se destaca para qual direção a transformação da exploração aponta: para a exploração da concentração" (TÜRCKE, 2010a, p. 274). O processo de divisão especializada do trabalho, enredado ao consumo incessante de choques audiovisuais disseminados pela indústria cultural, promove a dificuldade de os indivíduos se deterem sobre aquilo que está lhes exigindo atenção na medida em que a concentração é esfacelada. O autor esclarece que a concentração é "um demorar mental com algo" e quanto mais complexo o trabalho for, tanto mais é exigido do indivíduo o exercício de concentração. Porém, se o trabalho for demasiado simples, "[...] mais ele se compõe de meros 'torna-se concentrados', mais insuportável se torna dever concentrar-se no trabalho" (TÜRCKE, 2010a, p. 278, grifo do autor). A sociedade industrial capitalista, ao simplificar o processo de trabalho, deixando aos trabalhadores a tarefa de executar atividades banais que pouco contribuem para a sua formação, faz que o exercício de se concentrar aconteça em meio à dispersão de estímulos.

Desse modo, o autor assevera que um novo regime de atenção se consolida em função da dificuldade de se concentrar em algo que é provocado pelo consumo massivo do choque imagético. Distração concentrada é o nome dado por Türcke à forma contemporânea de concentração, pois "[...] de modo fulminante, o choque concentra a atenção num ponto, para poder triturar essa concentração através de incontáveis repetições. O meio de concentração é, propriamente, o meio de decomposição" (TÜRCKE, 2010a, p. 266). Assim, em tempos de excitação audiovisual, a simplificação do trabalho tem como consequência o esfacelamento da concentração. Essa distração é caracterizada pela dificuldade de se concentrar no que está sendo feito, por isso, várias atividades são realizadas ao mesmo tempo sem, no entanto, o envolvimento efetivo com nenhuma. Como esclarece o autor, estar on-line exemplifica a maneira como a distração concentrada acomete o indivíduo, pois muitas tarefas podem ser feitas simultaneamente. Para Türcke (2010a), é como 
se estando em um site outro suplicasse para ser acessado e nessa inquietação advinda da urgência de consumir o maior número de informações possíveis a concentração é dificultada. A figura que melhor exemplifica a distração concentrada foi analisada por Günther Anders e discutida por Türcke (2010a). Como afirma o autor, ela faz referência ao fenômeno do tempo de não trabalho norte-americano da década de 1950 representada pelo "homem tomando banho de sol, que bronzeia suas costas, enquanto seus olhos passeiam por uma revista ilustrada, seus ouvidos participam de uma partida esportiva, suas mandíbulas mascam uma goma" (TÜRCKE, 2010a, p. 43). Türcke (2010a) esclarece que o trabalhador está tão acostumado a ocupar-se durante o período de trabalho que, quando está em seu tempo livre, não consegue fazer outra coisa senão continuar a se manter ocupado. Nesses termos, como afirma Adorno (2010), o desenvolvimento dos modos de produção capitalista retirou os pressupostos necessários para a formação cultural, entre eles, a capacidade de experimentar o mundo. Desse modo, não se consegue vivenciar o tempo livre como tempo para se recuperar da atividade do trabalho, portanto, como tempo formativo. É possível asseverar que a figura do "homem tomando banho de sol" é o protótipo daquilo que mais tarde seria denominado por Türcke (2010a) de distração concentrada.

\section{Problematizações CRíticas ACERCA dA (IN)DISCIPLINA NA SOCIEDADE EXCITADA}

Nos estudos pedagógicos de Havenstein (2009), Pereira (2009), Moura (2010), Teixeira (2010), Nogueira (2010), Santos (2011) e Fonseca (2011) foi possível verificar uma espécie de crítica quanto ao entendimento da indisciplina como algo inato e aparentemente imutável, ou seja, ao modo naturalizado de tratar a indisciplina no processo de ensino e aprendizagem. No entanto, ao continuarem enfatizando a indisciplina como manifestação de resistência às normas estabelecidas, no início do século XXI, num contexto social que tem hoje valorizado a ultrapassagem de todos os limites, os estudos não consideraram como as transformações sociais têm produzido modificações, inclusive naquilo que se entende como disciplina e indisciplina. Tais transformações aparecem nos estudos de Türcke (2010a) acerca da sociedade excitada, sobretudo em relação à chamada "distração concentrada", que tem como principal característica a atenção em meio à dispersão de estímulos audiovisuais. Desse modo, os estudos pedagógicos contemporâneos não fizeram uma discussão sobre a (in)disciplina discente considerando o atual momento histórico em que alunos e também professores encontram cada vez mais dificuldades de permanecerem concentrados. Pode-se pensar que o processo de disciplinamento e a produção da indisciplina escolar têm sido afetados por um "novo regime de atenção", como observou Türcke (2010b). Ou seja, a capacidade de concentração que é esfacelada pelo consumo dos choques audiovisuais faz que os estudantes tenham enormes dificuldades de internalizar a disciplina, de modo que consigam demorar-se sobre o material estudado a fim de compreendê-lo.

Ao acentuarem a indisciplina como expressão de resistência às normas instituídas pela escola, os estudos acabaram resvalando naquilo mesmo que criticam, só que de uma forma diferente: considerando a resistência algo inerente aos alunos indisciplinados, acabaram por naturalizá-la. Nesse contexto, à medida que a indisciplina é compreendida na educação apenas como resistência ao poder, como aparece em Mendes (2009), Havenstein (2009), Teixeira (2010), Moura (2010), Santos (2011) e Fonseca (2011), perde-se a oportunidade de percebê-la no interior das relações sociais mais recentes, marcadas pelo avanço dos valores do mercado e da semiformação, que indicam um comportamento resignado frente à realidade estabelecida. Além disso, a indisciplina não foi discutida nesses estudos pedagógicos como um dos efeitos da crise da autoridade docente em que a figura do professor perdeu, ao longo do desenvolvimento científico-tecnológico, grande parte da im- 
portância que exercia na aprendizagem dos alunos, já que era visto como alguém fundamental para o processo de internalização da disciplina que ocorria durante a explicação e a aprendizagem dos conteúdos escolares.

No contexto de uma sociedade em que as pessoas são mobilizadas pelo imperativo de impressionar para serem percebidas, a indisciplina pode assumir uma forma nunca vista. Como um dos impasses pedagógicos, ela continua a existir na contemporaneidade, podendo ser pensada também como uma das consequências da distração concentrada. Ou seja, no contexto da sociedade excitada, a indisciplina mais se parece hoje expressão de uma norma social que forma indivíduos inaptos a se fixarem sobre algo e se deixarem interrogar por eles. Nesse sentido, algo que se afasta da ideia de resistência tal como compreendido nos estudos pedagógicos.

Desse modo, a dificuldade de permanecer trabalhando nos objetos de estudo para construir algo é expressão de uma época que explora continuamente a capacidade de concentração e afeta o processo de disciplinamento. Isso pode ser evidenciado na discussão feita por Türcke (2010a) sobre as mudanças na estrutura estética dos livros e jornais que intensificaram o uso de imagens nas páginas de textos impressos e digitais a fim de serem consumidos. Nas palavras do autor:

...cada um [dos] produtos, que deseja ser observado, deve imitar a técnica do choque imagético, de modo que precisa acercar-se violentamente dos olhos, tal como faz o choque. Não apenas os jornais sensacionalistas, mas também os mais conceituados não são mais percebidos caso não publiquem fotos coloridas. Suas páginas se tornaram "falantes", ou seja, se tornaram pobres de texto e ricas de imagens. E a forma do livro se alinha a isso (TÜRCKE, 2010a, p. 285).
É cada vez mais difícil voltar a atenção para textos que não possuem imagens, pois, como explica o autor, a leitura de linha por linha, página por página, tornou-se insuportável numa sociedade que promove continuamente a exploração da capacidade de atenção graças à disseminação do choque audiovisual. Dessa maneira, a leitura tornou-se semelhante, como afirma Türcke (2010a), ao zapping no uso do controle remoto quando se está assistindo televisão, pois do mesmo modo automatizado que se muda de canal a revista ou o livro é folheado. Assim, esse tipo de leitura marcado pela rapidez e descontinuidade distancia o indivíduo do encontro com a experiência ao não possibilitar que ele pense sobre o que está sendo lido. A leitura-zapping intensifica as manifestações de indisciplina escolar, distanciando o aluno da reflexão acerca daquilo que consome e a respeito de seu próprio comportamento. Desse modo, essa leitura não detida que acontece em meio à torrente de estímulos imagéticos contribui para que o estudante indisciplinado se conserve em sua própria heteronomia. Como consequência, a leitura que tem a preocupação de trabalhar sobre a palavra para compreender os objetos mediatos e imediatos é cada vez menos exercitada na medida em que as imagens sobrepujaram a palavra escrita.

O zapping por entre os canais de televisão, pelas páginas de uma revista ou pelo clicar simultâneo em diferentes sites, expressa uma falta de controle, de contenção diante das imagens que vão se sobrepondo umas às outras. A essa dificuldade de se fixar nos objetos está presente aquilo que Türcke (2010b) denominou de up to date, ou seja, a necessidade de acessar o maior número de objetos possíveis na busca por informações para estar sempre atualizado. O up to date é a atualização da semiformação em tempos de sociedade excitada, uma vez que é preciso buscar simultaneamente informações em diferentes locais sobre assuntos diversos, utilizando os aparatos tecnológicos e pouco se importando acerca do que está sendo consumido. Desse modo, conforme explica Adorno, "a experiên- 
cia [...] fica substituída por um estado informativo pontual, desconectado, intercambiável e efêmero, e que se sabe que ficará borrado no próximo instante por outras informações" (ADORNO, 2010, p. 33). No entanto, a capacidade humana de conseguir entrar em contato com novas informações, e principalmente apreendê-las, não acontece velozmente. A fim de conseguir apropriar-se das informações disponíveis, é preciso concentração, disciplina e tempo para se deter sobre aquilo que está requerendo atenção e a partir disso ressignificar e construir novos conceitos.

O up to date se manifesta, por exemplo, quando o professor não consegue fazer que os discentes participem da aula - o que expressa também o enfraquecimento de sua autoridade -, pois estão mais preocupados em acessar novas informações para se fazerem notados ao imergirem nas possibilidades interativas que a internet oferece. Assim, se mostram impacientes durante a explicação do conteúdo disciplinar, demonstrando dificuldades de prestarem atenção ao que está sendo dito. Desse modo, dão indícios de suas dificuldades para desempenhar de forma satisfatória as tarefas propostas na medida em que não há um entendimento em relação àquilo que foi solicitado. Podemos perceber um desinteresse pela própria formação que se manifesta nas reclamações e má vontade dos discentes em realizar as tarefas requeridas pelo professor. Nesses termos, no epílogo intitulado "Tempo de Sonho High-Tech", da obra "Filosofia do sonho", Türcke (2010b) assevera que um "novo regime de atenção" consolida-se graças à dificuldade de se concentrar em algo que é provocado pelo consumo massivo do choque imagético. Nesse sentido, o autor afirma que "[...] as próprias imagens impedem que alguém nelas se demore, medite sobre elas, reelabore-as, detenha-se nelas" (TÜRCKE, 2010b, p. 318). Como a própria forma que as imagens são produzidas dificulta o exercício de pensar sobre elas, o autor entende que precisamente por isso o processo de disciplinamento é essencial para a formação por permitir a construção de mo- mentos em que seja possível experienciar algo por meio do trabalho demorado sobre os objetos. Desse modo, na medida em que o autor concebe o updating como "[...] a dessedimentação do estofo glúteo de sentar para pensar" (TÜRCKE, 2010b, p. 319), entendemos que o processo de disciplinamento oferece justamente as condições para que esse estofo seja formado, pois a disciplina permite não apenas permanecer nos objetos, mas se deixar interrogar por eles, de modo que seja possível interpretá-los e ressignificá-los.

Nesse sentido, arriscamo-nos a dizer que, ao contrário do que as dissertações sobre disciplina e indisciplina afirmam, o processo de disciplinamento na realidade social constituída não produz alunos conformados e submissos, mas capazes de se oporem à realidade imposta ao fazerem uso de sua capacidade crítica. Sendo assim, os alunos disciplinados estão mais próximos de construírem um pensamento autônomo quando comparados aos indisciplinados, pois a indisciplina está relacionada a uma espécie de manutenção da heteronomia.

Desse modo, Türcke (2010a) permite compreender que a necessidade de ser percebido intensifica as manifestações de indisciplina, já que os discentes estão mais voltados para os aparatos tecnológicos com o intuito de produzirem uma imagem e, com isso, se fazerem notados do que efetivamente envolvidos com os materiais de estudo. Além disso, de acordo com Rodrigues e Farias (2012), o medo de não ser percebido afeta a capacidade de se deter em algo, uma vez que estando preocupado em emitir constantemente o aluno passa a se relacionar apressadamente com os objetos. Logo, demorar-se em tais objetos e se deixar interrogar por eles passa a instalar uma desconfiança no aluno de que está perdendo tempo e oportunidades de se tornar notado. A compulsão pela ocupação também contribui para intensificar as manifestações indisciplinadas na medida em que estar sempre ocupado distancia o aluno do trabalho demorado com os objetos. Isso porque quanto mais o aluno se mantém ocu- 
pado, tanto menos consegue relacionar-se efetivamente com os materiais de estudo, já que essa ocupação permanente e simultânea revela o não se ocupar com nada.

Nesse contexto em que as tecnologias são usadas para atender à compulsão pela emissão e pela ocupação, ressaltamos que o desenvolvimento cultural e científico-tecnológico não foi considerado nas dissertações analisadas neste artigo como um dos elementos que vêm mobilizando o comportamento dos estudantes e contribuindo para as ocorrências de indisciplina. A respeito da importância de considerar a relação entre o desenvolvimento tecnológico e a indisciplina, destacamos a discussão de Adorno sobre a presença das tecnologias na vida das pessoas, quando afirma que "um mundo em que a técnica ocupa uma posição tão decisiva como acontece atualmente, gera pessoas tecnológicas, afinadas com a técnica" (ADORNO, 1995, p. 132). Desse modo, o desenvolvimento técnico-científico tem contribuído para a ressignificação da indisciplina discente e para a não construção da reflexão crítica ao mesmo tempo em que tem provocado uma espécie de regressão na totalidade do indivíduo, tanto em sua capacidade de pensar quanto de sentir. Tal desenvolvimento tem contribuído ainda para promover o contato acrítico com as tecnologias utilizadas para atender ao imperativo do "Ser, é ser percebido" e, com isso, provocado mudanças na capacidade de concentração dos discentes, pois o choque imagético proporcionado por esses aparatos altera a forma como o indivíduo lida com os objetos. Nesse sentido, o trabalho sobre os materiais de estudo tem acontecido cada vez mais de maneira fragmentada, pontual e descontextualizada, dificultando a construção de um conhecimento que resulte da relação demorada com os objetos. Essa relação aligeirada com os materiais de estudo que se reverbera no consumo ininterrupto de imagens proporcionado pelas tecnologias contribui para as manifestações de dispersão da concentração.

Nesse sentido, as dissertações analisadas revelaram uma despreocupação em analisar o fenômeno da (in)disciplina considerando os elementos extrapedagógicos que interferem na relação entre professores e alunos e no processo educativo e que modificam, inclusive, o comportamento dos agentes educacionais diante da construção do conhecimento. E outro exemplo disso aparece no modo de se referir às configurações familiares sem considerar a autoridade como um elemento formador das subjetividades. Ao entenderem a disciplina como sinônimo de acomodação, subordinação e obediência enquanto a indisciplina é concebida como resistência e até mesmo como uma espécie de "inteligência", tais dissertações compreenderam o processo de disciplinamento apenas como meio de formar sujeitos docilizados, acríticos, submissos e não contestadores.

\section{CONSIDERAÇÕES FINAIS}

Os estudos pedagógicos, ao fazerem a crítica à disciplina, considerando a indisciplina como resistência às normas instituídas pela escola, acabaram concebendo-a como conformismo, acomodação e obediência. Ao tratarem a indisciplina como sinônimo de resistência, tais estudos não apenas negaram a dimensão formativa da disciplina, como também, desconsideraram o poder que a realidade extraescolar exerce sobre as questões educacionais. A onipresença das imagens audiovisuais também não foi considerada como um elemento importante, que tem alterado a maneira de agir e pensar de professores e alunos. Nesses termos, preocupados em revelar as causas da indisciplina discente, os estudos pedagógicos consideraram a família como a principal responsável pelas manifestações indisciplinadas sem, contudo, discutir a importância da autoridade para a construção psíquica dos sujeitos e para o processo de disciplinamento. Esses estudos também destacaram a necessidade de repensar a escola, especialmente no que se refere à formação de professores, pois consideraram que uma das atitudes que contribuem para a manutenção da indisciplina escolar é o despreparo docente para lidar com os comportamentos indisciplinados. 
Nesse sentido, é necessário destacar que a disciplina e a indisciplina no processo formativo precisam ser permanentemente pensadas dentro do contexto social em que as formas técnicas e tecnológicas de vida avançam. Sendo assim, este artigo entende que a discussão acerca da dimensão formativa da disciplina e a respeito das manifestações da indisciplina deve acontecer considerando a onipresença das imagens audiovisuais como um elemento que tem formado o comportamento dos agentes educacionais nas escolas. Por isso, podemos asseverar que o processo de disciplinamento é algo contínuo que envolve a construção de uma relação com os materiais de estudo marcada pela permanência, retenção e reflexão sobre os objetos trabalhados. Nesse sentido, discordamos das dissertações analisadas que entendem a indisciplina como equivalente à resistência desconsiderando a dimensão formativa da disciplina. Pois consideramos a disciplina como resistência aos choques audiovisuais que proporcionam a não permanência nos objetos, enquanto a indisciplina pode ser entendida como sinônimo de acomodação e de conformismo, na medida em que contribui para a manutenção da heteronomia.

Desse modo, considerando as discussões de Adorno e Türcke apresentadas neste trabalho, reiteramos a necessidade da disciplina e da indisciplina no processo educativo serem analisadas no interior das relações sociais, considerando o desenvolvimento da cultura e o aperfeiçoamento técnico-científico. Portanto, compreendemos a disciplina como um momento fundamental do processo educativo comprometido com a construção de um pensamento crítico e autodeterminado. Nesses termos, realçamos a importância de analisar os fenômenos educacionais considerando o poder que a realidade extrapedagógica exerce sobre a formação das pessoas no espaço escolar, visto que o desenvolvimento científico e tecnológico com o consumo irrefletido do choque audiovisual por professores e alunos tem promovido mudanças nas formas de pensar, sentir e se relacionar com os materiais de estudo, prejudicando a construção da disciplina e intensificando as manifestações de indisciplina escolar.

A compreensão da indisciplina como sinônimo de resistência foi discutida principalmente nas dissertações de Mendes (2009), Havenstein (2009), Teixeira (2010), Moura (2010), Santos (2011) e Fonseca (2011), não havendo em qualquer delas o questionamento se a indisciplina poderia ser ou se tornar algo que indica o contrário de resistência. Além disso, ao tratar a indisciplina apenas como resistência, os estudos omitem qualquer indício de que a disciplina é considerada por estudiosos e professores como um momento indispensável ao processo formativo. A dicotomia que compreende a indisciplina como resistência e a disciplina como docilização produzida com a organização dos espaços e tempos escolares parece desviar o pensar das consequências humanas trazidas com o desenvolvimento científico e tecnológico, de considerá-las como um elemento que tem mobilizado o comportamento dos alunos nas instituições de ensino.

Desse modo, os estudos pedagógicos, ao fixarem o momento de resistência na indisciplina, dispensam-se de continuar pensando-a no interior da cultura contemporânea do choque midiático que se expande como condição para formar subjetividades cada vez menos afeitas ou capazes de se deterem. Ou seja, nesse contexto, a indisciplina que hoje é evocada por todos os cantos sociais e acena muito mais para a acomodação à realidade estruturada sob a lógica do lucro, continua sendo compreendida nas abordagens estudadas apenas como índice de resistência aos controles escolares. Isto é, neste momento histórico de realização de uma cultura que não cessa de excitar as pessoas, mobilizando o consumismo e o produtivismo, as abordagens a respeito da disciplina e indisciplina assumem, um momento de inverdade, ao prenderem a ideia de resistência à indisciplina, dificultando pensar o desenvolvimento da disciplina como um momento tornado ainda mais importante no processo formativo, dadas as condições sociais presentes. 


\section{REFERÊNCIAS}

ADORNO, T. W. Teoria da semiformação. In: PUCCI, B.; ZUIN, A. A. S.; LASTÓRIA, L. A. C. N. (Orgs.). Teoria crítica e inconformismo: novas perspectivas de pesquisa. Campinas: Autores Associados, 2010.

ADORNO, T. W. Educação e emancipação, 4. ed.. Trad. Wolfgang Leo Maar. Rio de Janeiro: Paz e Terra, 1995.

FONSECA, A. de C. "Disciplinando o corpo de Alice: maravilha e controle na escola contemporânea”, 2009, 101s. Dissertação (Mestrado em Educação). Faculdade de Educação, Universidade Federal de Juiz de Fora, Juiz de Fora.

FOUCAULT, M. Vigiar e Punir: nascimento da prisão. Trad. Raquel Ramalhete, 38. ed. Petrópolis: Vozes, 2010.

GROSS, I. “Discurso pedagógico sobre indisciplina escolar”, 2009, 1145. Dissertação (Mestrado em Educação). Departamento de Educação, Universidade Tuiuti do Paraná, Curitiba.

HAVENSTEIN, S. W. "Letrinha bonita, corpinho quieto e boquinha fechada: um estudo sobre os mecanismos disciplinares em classes de alfabetização”, 2009, 73s. Dissertação (Mestrado em Educação). Centro de Ciências da Educação, Universidade Regional de Blumenau, Blumenau.

MENDES, F. M. D. “Indisciplina escolar na visão de coordenadores pedagógicos”, Curitiba/PR, 2009, 126s. Dissertação (Mestrado em Educação). Departamento de Educação, Universidade Tuiuti do Paraná, Curitiba.

MOURA, T. M. de. "Foucault e a escola: disciplinar, examinar, fabricar”, 2010, 955. Dissertação (Mestrado em Educação). Faculdade de Educação, Universidade Federal de Goiás, Goiânia.

NOGUEIRA, Y. P. de A. “Política de formação do professor de Educação Física e indisciplina escolar", 2010, 117s. Dissertação (Mestrado em Educação). Centro de Teologia e Ciências Humanas, Pontifícia Universidade Católica do Paraná, Curitiba.

PEREIRA, M. A. da S. "Indisciplina escolar: concepções dos professores e relações com a formação docente”, 2009, 149s. Dissertação (Mestrado em Educação). Departamento de Educação, Universidade Católica Dom Bosco, Campo Grande.

RODRIGUES, L. A.; FARIAS, M. N. A desatenção como um eco da paixão pelo real. Educação em Revista, Belo Horizonte, v. 28, n. 1, p. 441-458, mar. 2012. Disponível em: <http://www.scielo. $\mathrm{br} / \mathrm{scielo}$.php?script=sci_arttext\&pid=S0102-46982012000100019\&Ing=en\&nrm=iso $>$. Acesso em 9 nov., 2016.

SANTOS, L. G. dos. “Os significados da indisciplina na escola”, 2011, 117s. Dissertação (Mestrado em Educação). Departamento de Educação, Universidade Tuiuti do Paraná, Curitiba.

TEIXEIRA, A. "Cenas de uma escola contemporânea: uma geração indisciplinada ou uma geração de novos sujeitos?" 2010, 101s. Dissertação (Mestrado em Educação). Departamento de Educação, Universidade Luterana do Brasil, Canoas.

TÜRCKE, C. Sociedade excitada: filosofia da sensação, 1. ed. Trad. Antonio A. S. Zuin... [et al.]. Campinas: Editora da Unicamp, 2010a.

TÜRCKE, C. Filosofia do sonho, 1. ed. Trad. Paulo Rudi Schneider. ljuí: Editora da Unijuí, $2010 b$. 


\section{DAdOS DAS AUTORAS}

\section{Camila Sandim de Castro}

Doutoranda em Educação pela Universidade Federal de São Carlos. São Carlos/SP - Brasil. camila_sandim@yahoo.com.br

\section{Luciana Azevedo Rodrigues}

Graduada em Design de Interface Digital pela Fundação Centro de Análise Pesquisa e Inovação Tecnológica. Manaus/AM - Brasil. lunazevedo@gmail.com

Submetido em: 10-6-2015

Aceito em: 27-12-2016 